\title{
Pengaruh Kepemimpinan Transformasional Dan Kepuasan Kerja Terhadap Komiten Afektif Karyawan
}

\author{
Gilang Ananda Mikola dan Arif Partono Prasetio \\ Universitas Telkom \\ e-mail: gilangmk120@gmail.com dan partono67@gmail.com \\ Diterima: November 2019; Dipublikasikan Januari 2020
}

\begin{abstract}
ABSTRAK
Penelitian ini bertujuan untuk menganalisis pengaruh kepemimpinan transformasional dan kepuasan kerja terhadap komitmen afektif karyawan yang ada di Industri Genteng Jatiwangi. Kuisioner yang disebarkan sebanyak 200 dan yang dikembalikan sebanyak 200 juga. Penelitian ini menggunakan teknik analisis data berupa analisis deskriptif dan analisis jalur. Hasil penelitian membuktikan bahwa gaya kepemimpinan transformasional dan kepuasan kerja memiliki pengaruh parsial dan simultan terhadap peningkatan komitmen afektif karyawan. Organisasi perlu mengaplikasikan gaya kepemimpinan transformasional serta mengembangkan program sumberdaya manusia yang bisa meningkatkan kepuasan kerja karyawan. Dengan mengoptimalkan kedua unsur ini, organisasi diharapkan mampu meningkatkan komitmen afektif karyawan.
\end{abstract}

Kata Kunci: kepemimpinan transformasional; kepuasan kerja; komitmen afektif.

\begin{abstract}
This study aims to analyze the effect of transformational leadership and job satisfaction on the affective commitment of employees in the Jatiwangi Roofing Industry. 200 questionnaires were distributed and 200 were returned as well. This study uses data analysis techniques in the form of descriptive analysis and path analysis. The results of the study prove that transformational leadership style and job satisfaction have a partial and simultaneous influence on increasing employee affective commitment. Organizations need to apply transformational leadership styles and develop human resource programs that can increase employee job satisfaction. By optimizing these two elements, the organization is expected to be able to increase employee affective commitment.
\end{abstract}

Keywords: transformational leadership; job satisfaction; affective commitment. 


\section{PENDAHULUAN}

Perusahaan yang mampu bersaing di pasar persaingan adalah perusahaan yang memiliki sumber daya manusia yang berkualitas dan kompetitif. Sumber daya manusia yang berkualitas dapat membuat suatu organisasi unggul dalam hal kinerja dan kemajuannya. Dalam hal ini dapat diperhatikan bahwa diperlukannya pengelolaan sumber daya manusia yang baik di dalam suatu perusahaan. Kalangi (2015) mengungkapakan bawa di era persaingan global yang ketat, sumber daya manusia dianggap sebagai salah satu faktor yang paling penting memainkan peran utama dalam menjaga keberlanjutan organisasi, kredibilitas serta penciptaan kepercayaan publik. Sumber daya manusia memungkinkan perusahaan untuk memperluas dan beradaptasi dengan lingkungan yang seragam serta memudahkan karyawan dalam menerapkan strategi kreatif dan inovatif (Javed et al., 2017). Sumber daya manusia yang dapat memberikan kontribusi ke perusahaan adalah sumber daya yang dapat membangun ikatan emosional yang kuat atau komitmen afektif yang kuat di dalam suatu perusahaan agar dapat menjalankan tujuan yang sama. Kontribusi bisa tercapai apabila karyawan memiliki komitmen afektif yang kuat. Susilawati (2018) menyatakan bahwa komitmen afektif menunjukkan kesesuaian nilai-nilai karyawan dengan nilai-nilai organisasi serta semakin kuat ikatan emosional yang dimiliki akan memberikan kontribusi yang baik bagi perusahaan. Karayawan yang memiliki komitmen emosional yang kuat maka akan memiliki moral yang tinggi dan sangat puas dengan pekerjaan mereka maka karyawan akan memberikan kontribusi untuk perusahaan (Saha \& Kumar, 2018).

Karyawan yang memiliki komitmen afektif yang kuat merupakan unsur utama dalam membantu perusahaan untuk mencapai sasaran organisasi. Casimir et al. (2014) menjelaskan bahwa untuk meningkatkan komitmen afektif karyawan ada beberapa faktor yaitu leader-member exchange (LMX) dan dukungan oraganisasi yang dirasakan (POS). Beberapa faktor lain yang juga dapat membantu meningkatkan komitmen emosional dalam diri karyawan adalah keyakinan atas diri sendiri (Giovanita \& Mangundjaya, 2017) kepemimpinan transformasional (Dlamini et al., 2017), kepuasan kerja (Nazneen \& Miralam, 2017), kekuatan manajerial (Jalilvand \& Vosta, 2015), masa jabatan organisasi (English et al., 2010), persepsi tanggung jawab sosial perusahaan (Allen et al., 2017), kepemimpinan etis (Loi et al., 2015), keadilan prosedural (Charbonneau \& Wood, 2018), pekerjaan tidak standar dan keseimbangan kehidupan kerja (Omar, 2015). Keragaman faktor yang ada dapat membantu meningkatkan komitmen afektif karyawan akan memudahkan organisasi dalam memiliki program yang kelak akan diterapkan. Penelitian ini membahas tentang pengaruh langsung dan tidak langsung kepemimpinan transformasional terhadap komitmen afektif melalui mediasi kepuasan kerja. Kepemimpinan transformasional dan kepuasan kerja menjadi salah satu faktor yang dapat meningkatkan komitmen afektif yang kuat terhadap perusahaan. Ketika seorang pemimpin dapat melibatkan karyawan dan secara tidak langsung menyuruh karyawan untuk mengembangkan potensinya itu akan membuat sebuah ikatan emosional yang kuat di dalam perusahaan. Selain itu kepuasan kerja juga dapat meningkatkan komitmen afektif yang kuat karyawan ketika kepuasan kerja yang dibutuhkan sudah terpenuhi seperti gaji, kompensasi,lingkungan kerja, atasan, dan promosi..

Penelitian ini dilakukan pada industri yang bergerak di bidang genteng Jatiwangi. Industri genteng yang berada di Jatiwangi rata-rata adalah perusahaan swasta yang dimana memiliki target bisnisnya masing-masing. Tercapainya target merupakan tujuan utama dari sasaran bisnis perusahaan yang berada di Industri tersebut. Karyawan yang berkerja dengan optimal dan sukarela diperusahaan akan menjadi pendukung dalam mencapai keberhasilan. Berdasarkan hasil wawancara dengan pemilik perusahaan 
genteng di Jatiwangi bahwa tingkat komitmen afektif karyawan masih belum bisa dirasakan sepenuhnya. Hal tersebut bisa dirasakan ketika masih sedikitnya karyawan yang memberikan kontribusi lebih, masih ada beberapa karyawan yang tidak tertib dalam pekerjaan, dan masih adanya yang belum mencapai target pekerjaannya. Karyawan masih menjadikan pekerjaan sebagai beban yang harus diselesaikan bukan untuk mengembangkan perusahaan dan diri sendiri.

Data yang didapatkan bahwa tingkat rata-rata target kerja yang berada di industri ini ada diangka $83 \%$ dan masih jauh dari target yang ditetapkan. Data yang didapat mengindikasikan bahwa tingkat komitmen karyawan terhadap perusahaan sudah belum kuat dan perlu ditingkatkan. Berdasarkan Hasil yang didapat diatas walaupun masih belum mencapai target yang ditetapkan dan menurut hasil wawancara belum merepresentasikan komitmen afektif sudah dirasakan sepenuhnya oleh organisasi. Untuk meningkatkan komitmen afektif di Industri tersebut penelitian ini memilih 2 pendeketan yaitu kepemimpinan transformasional dan kepuasan kerja yang di harapkan mampu menjadi faktor yang berpengaruh dalam peningkatan komitmen afektif yang ada di perusahaan. Penelitian ini ingin mengetahui apakah gaya kepemimpinan transformasional di industri ini diterapkan sudah efektif. Selain itu, ingin mengukur bagaimanakah tingkat kepuasan kerja yang ada di industri genteng Jatiwangi ini. Selanjutnya adalah mengidentifikasi apakah kepemimpinan transformasional dan kepuasan kerja dapat menjadi faktor peningkatan komitmen afektif di industri tersebut. Penelitian ini diharapkan menjadi jawaban yang akurat untuk manajemen dalam melakukan program atau kebijakan manajemen sumber daya manusia yang efektif untuk industri ini.

\section{Kepemimpinan Transformasional}

\section{TINJAUAN PUSTAKA}

Kepemimpinan transformasional adalah gaya pemimpin yang memberdayakan para pengikut secara individu untuk mengembangkan, meningkatkan kemampuan mereka, dan meningkatkan efektifitas diri karyawannya (Robbins dan Judge, 2015:264). Kepemimpinan transformasional merupakan suatu proses dimana individu berinteraksi dengan individu lain dan menciptakan suatu hubungan yang meningkatkan motivasi dan moralitas dalam diri pemimpin serta pengikutnya (Northouse, 2016:166). Pemaparan beberapa definisi diatas yang dijelaskan para ahli dapat disimpulkan bahwa kepemimpinan transformasional adalah gaya pemimpin yang memberdayakan para pengikut secara individu untuk mengembangkan, meningkatkan kemampuan mereka, meningkatkan efektifitas diri karyawannya, dan melibatkan perubahan.

\section{Kepuasan Kerja}

Kepuasan kerja menurut Priansa (2017:18) merupakan sekumpulan perasaan karyawan terhadap pekerjaannya, apakah senang atau tidak sebagai hasil interaksi karyawan dengan lingkungan pekerjaannya dan juga sebagai hasil penilaian karyawan terhadap pekerjaannya. Definisi lain menyatakan bahwa kepuasan kerja adalah suatu perasaan positif yang muncul tentang pekerjaan yang dihasilkan dari suatu evaluasi dari karakteristik-karakteristik kerjanya. (Robbins \& Judge, 2015:46). Kepuasan kerja menurut Ivancevich et al. (2014:71) adalah sikap seseorang terhadap pekerjaannya dari persepsi mereka tentang pekerjaan dan sejauh mana ada kecocokan yang baik antara mereka sebagai individu dan organisasi. Berdasarkan definisi yang dipaparkan para ahli diatas dapat disimpulkan bahwa kepuasan kerja adalah suatu perasaan positif karyawan tentang pekerjaan senang atau tidak dengan lingkungan kerja, interaksi karyawan, dan karakteristik-karakteristik kerjanya. 


\section{Komitmen Afektif}

Komitmen afektif merupakan keterkaitan perasaan emosional dari pegawai serta mengidentifikasi keterlibatannya dalam organisasi (Edison et al., 2015:226). Definisi lain yang dikemukakan oleh Meyer \& Allan (1991) menjelaskan bahwa komitmen afektif mencerminkan keinginan unutk mempertahankan keanggotaan dalam organisasi yang berkembang sebagai hasil dari pengalaman kerja yang menciptakan perasaan nyaman dan kompetensi pribadi. Komitmen afektif didefinisikan sebagai keinginan untuk tetap menjadi anggota suatu organisasi karena keterikatan emosional dengan keterlibatan organiasi (Colquitt et al., 2014:65). Pemaparan defisini komitmen afektif yang dijelaskan oleh para ahli diatas dapat disimpulkan bahwa komitmen afektif adalah keinginan untuk tetap menjadi anggota organisasi dikarenakan adanya keterikatan emosional terhadap perusahaan.

\section{Variabel Penelitian}

\section{METODE PENELITIAN}

Variabel adalah karakteristik yang akan di observasi dari satuan pengamatan (Supardi,2013:22). Penelitian ini menggunakan dua jenis variabel yaitu independen dan dependen. Variabel Independen menurut Supardi (2013:24) adalah variabel yang menjadi penyebab munculnya variabel lain dan secara tidak langsung yaitu variabel yang mempengaruhi variabel lain. Adapun variabel independen pada penelitian ini adalah Kepemimpinan Transformasional dan Kepuasan Kerja Sedangkan Variabel dependen menurut Supardi (2013:24) adalah variabel yang keberadaannya dipengaruhi oleh variabel lain. Variabel ini merupakan variabel yang dipengaruhi oleh variabel- variabel lainnya. Variabel dependen pada penelitian ini adalah Komitmen Afektif.

\section{Populasi dan Sampel}

Taniredja \& Mustafidah (2011:33) menjelaskan bahwa populasi adalah semua anggota sekelompok orang kejadian atau obyek yang telah dirumuskan secara jelas. Karakteristik populasi yang ditentukan dalam penelitian ini adalah pria atau wanita, usia minimal 20 tahun, minimal bekerja 1 tahun, dan bekerja sampai dengan 9 jam atau lebih. Populasi yang ada di 4 perusahaan yang berada pada industri tersebut sebanyak 200 orang. Supardi (2013:26) menjelaskan bahwa sampel adalah bagian dari populasi yang mempunyai ciri-ciri atau keadaan tertentu yang akan diteliti. Sementara untuk teknik pengambilan sampel, penelitian ini menggunakan non probability sample dengan kategori sampling jenuh atau pengambilan sampel keseluruhan dalam populasi dilibatkan dengan sampel penelitian (Adams et al., 2012:75). Adapun alasan penulis dalam menggunakan teknik tersebut adalah karena jumlah populasi sebanyak 200 orang karyawan ada agar penulis dapat meminimalisir kemungkinan kesalahan serta akan memudahkan dalam melakukan penelitian dan mempercepat proses penelitian.

\section{Uji Validitas}

Uji Validitas adalah kriteria yang paling kritis dan menunjukkan sejauh mana instrumen mengukur apa yang seharusnya diukur. Validitas berhubungan dengan ketepatan alat ukur untuk melakukan tugasnya dalam mencapai sasaran (Sujarweni, 2015:192). Berikut merupakan tabel yang menjelaskan hasil pengujian validitas opersional variabel. Item yang diuji dikatakan valid jika memenuhi syarat yaitu memiliki nilai $r$ hitung $>r$ tabel dengan Sig. $<0.05 \mathrm{df}=n-2$. Jika memenuhi syarat tersebut maka item tersebut dinyatakan valid. 


\section{Uji Reliabilitas}

Sujarweni (2014:192) menjelaskan bahwa reliabilitas adalah indeks yang menunjukkan sejauh mana suatu alat ukur dapat dipercaya atau diandalkan. Suatu alat ukur dikatakan reliabel bila alat itu dalam mengukur suatu gejala pada waktu yang berlainan senantiasa menunjukkan hasil ukuran yang sama (Taniredja \& Mustafidah, 2011:43). Untu mengukur reliabilitas adalah dengan membandingkan nilai korelasi keseluruhan (Cronbach's Alpha) dengan nilai r tabel. Jika nilai Cronbach's Alpha >0,60 maka instrumen tersebut adalah reliabel (Sujarweni,2014:192).

\section{Analisis Jalur}

Analisis jalur ialah suatu teknik untuk menganalisis hubungan sebab akibat yang terjadi pada regresi berganda jika variabel bebasnya mempengaruhi variabel tergantung tidak hanya secara langsung tetapi juga secara tidak langsung (Riduwan \& Kuncoro, 2017:2). Penelitian ini menggunakan analisis jalur untuk mengetahui pengaruh langsung dan pengaruh tidak langsung kepemimpinan transformasional terhadap komitmen afektif melalui variabel kepuasan kerja. Berikut rumus untuk menentukan koefisien jalur (p) yang diturunkan berdasarkan koefisien korelasi sederhana.

$$
\mathrm{Y}=\mathrm{p}_{\mathrm{yx} 1} \mathrm{X}_{1}+\mathrm{p}_{\mathrm{yx} 2} \mathrm{X}_{2}+p_{\mathrm{y}} \varepsilon
$$

\section{HASIL DAN PEMBAHASAN}

\section{Karakteristik Responden}

Penelitian ini menggunakan 200 responden. Jumlah kuisioner yang disebarkan sebanyak 400 buah, dengan demikian diperoleh tingkat pengembalian sebesar $50 \%$. Meski tidak terlalu besar dan kecil, jumlah ini sudah bisa mewakili populasi karyawan di industri yang menjadi sasaran penelitian. Profil responden dijelaskan dalam beberapa kategori. Rasio gender responden adalah $82 \%$ pria dan $18 \%$ wanita. $32 \%$ dari mereka berusia di antara 35-40 tahun. Sebagian besar berpendidikan hingga tingkat sekolah dasar $(60 \%)$. Mengenai masa kerja, 30\% telah bekerja antara 5 hingga 10 tahun. Sebanyak 83\% responden memilki posisi sebagai officer di perusahaan. Deskripsi detail tersedia di Tabel 1.

\section{Uji Validitas}

Berdasarkan perhitungan yang dilakukan diketahui bahwa $100 \%$ dari item pertanyaan variabel kepemimpinan transformasional dan kepuasan kerja valid dengan nilai sig. $<0,05$ atau instrumen pertanyaan dapat digunakan sebagai alat ukur variabel yang akan diteliti. Sementara hasil uji validitas untuk variabel komitmen afektif juga memaparkan hasil 100\% dari item pertanyaan valid dengan nilai sig. <0,05. Dengan demikian dari 38 pernyataan yang ada, 38 pernyataan dapat digunakan sebagai alat ukur variabel yang akan diteliti.

\section{Uji Reliabilitas}

Ukuran kepemimpinan transformasional menggunakan 16 item yang dikembangkan oleh Basyak dan Yener (2015) yang terdiri dari charismatic inspirational, pertimbangan individu, dan kecerdasan stimulasi. Alpha cronbach yang didapat sebesar 0,909. Sedangkan Kepuasan kerja diukur menggunakan 15 item yang dikembangkan oleh Prasetio et al. (2017) yang terdiri gaji, karir, pekerjaan itu sendiri, atasan, dan rekan kerja. Alpha cronbach yang didapat sebesar 0,927. Terakhir, Komitmen afektif diukur dengan 7 item yang diadaptasi dari Allen dan Meyer (1991). Alpha Cronbach yang 
didapatkan sebesar 0,723. Sehingga dapat disimpulkan bahwa kuisioner masing-masing indikator reliabel.

Tabel 1. Partisipan

\begin{tabular}{|c|c|c|c|}
\hline Demografik & Kategori & Partisipan & Persentase \\
\hline \multirow[t]{2}{*}{ Jenis Kelamin } & Pria & 164 & $82 \%$ \\
\hline & Wanita & 36 & $18 \%$ \\
\hline \multirow[t]{7}{*}{ Usia } & $<25$ tahun & 3 & $2 \%$ \\
\hline & $>25-30$ tahun & 60 & $30 \%$ \\
\hline & $>30-35$ tahun & 38 & $18 \%$ \\
\hline & $>35-40$ tahun & 64 & $32 \%$ \\
\hline & $>40-45$ tahun & 23 & $12 \%$ \\
\hline & $>45-50$ tahun & 3 & $2 \%$ \\
\hline & $>50$ tahun & 9 & $4 \%$ \\
\hline \multirow[t]{6}{*}{ Pendidikan } & $\mathrm{SD}$ & 122 & $60 \%$ \\
\hline & SMP & 49 & $24 \%$ \\
\hline & SMA & 27 & $14 \%$ \\
\hline & Diploma & 1 & $1 \%$ \\
\hline & S1 & 1 & $1 \%$ \\
\hline & $\mathrm{S} 2 / \mathrm{S} 3$ & 0 & $0 \%$ \\
\hline \multirow[t]{5}{*}{ Lama Bekerja } & $<1$ tahun & 5 & $3 \%$ \\
\hline & $1-3$ tahun & 52 & $26 \%$ \\
\hline & $>3-5$ tahun & 56 & $28 \%$ \\
\hline & $>5-10$ tahun & 60 & $30 \%$ \\
\hline & $>10$ tahun & 27 & $13 \%$ \\
\hline \multirow[t]{3}{*}{ Posisi } & Officer & 165 & $83 \%$ \\
\hline & Supervisor & 25 & $12 \%$ \\
\hline & Manager & 10 & $5 \%$ \\
\hline
\end{tabular}

Sumber: Data Diolah.

\section{Analisis Jalur}

Tabel 2 memperlihatkan korelasi antar variabel yang dibahas dalam penelitian ini. Terlihat bahwa kepemimpinan transformasional memiliki korelasi yang tidak terlalu kuat dengan tingkat kepuasan kerja karyawan (0.581). korelasi antara gaya transformasional dengan komitmen afektif juga relatif agak tinggi meski termasuk dalam kategori sedang (0.422). Sedangkan kepuasan kerja juga memiliki korelasi yang sedang dengan komitmen afektif (0.566). Hal ini berarti kedua variabel independen memiliki hubungan yang positif satu sama lain. Di samping itu keduanya juga memiliki korelasi positif dengan variabel independen. Jika gaya kepemimpinan transformasional diterapkan dengan baik, maka kepuasan dan komitmen afektfi akan meningkat. 
Tabel 2: Korelasi

\begin{tabular}{lccc}
\hline \multicolumn{1}{c}{ Keterangan } & $\mathbf{1}$ & $\mathbf{2}$ & $\mathbf{3}$ \\
\hline Transformasional & 1 & & \\
Kepuasan Kerja & $.581^{* *}$ & 1 & \\
Komitmen Afektif & $.422^{* *}$ & $.566^{* *}$ & 1 \\
\hline
\end{tabular}

Sumber: Data Diolah.

Sebelum melakukan analisis jalur, ada beberapa syarat yang harus dilakukan yaitu uji asumsi klasik yang terdiri dari uji normalitas, uji multikolinieritas, dan uji heteroskedastisitas. Hasil uji asumsi klasik yang dilakukan pertama adalah uji normalitas dan menemukan bahwa data dalam penelitian ini berdistribusi normal. Uji KolmogorovSmirnof mendapatkan nilai signifikansi 0.200 yang berarti lebih dari 0.05 . Hasi uji multikoliniearitas memperoleh nilai 0.662 untuk tolerance dan 1,551 untuk VIF. Dengan demikian tidak terjadi multikoliniearitas jika dibandingkan dengan standar tolerance di atas 0.10 dan VIF harus berada di bawah 10. Uji asumsi klasik terakhir adalah heterokedastisitas. Hasil yang didapatkan dengan menggunakan uji koefisien korelasi Spearman's Rho memperlihatkan bahwa nilai signifikansi antara variabel independen dengan Absolut Residual di atas 0.05. Dengan demikian tidak terjadi gejala heterokedastisitas. Setelah lolos uji asumsi klasik, maka data diolah menggunakan SPSS untuk memperoleh hasil penelitian. Tabel 3 menyajikan informasi mengenai korelasi (R) dan hubungan $\left(\mathrm{R}^{2}\right)$. Hubungan antara dua variabel independen dan variabel dependen tidak terlalu kuat (0.578). Sedangkan pengaruh keduanya terhadap komitmen afektif sebesar 0.334 atau $33,4 \%$.

Tabel 3. Model Summary

\begin{tabular}{lccc}
\hline Model & R & R Square & Adjusted R Square \\
\hline 1 &, $578^{\mathrm{a}}$ &, 334 &, 327 \\
\hline
\end{tabular}

Sumber: Data Diolah.

Tabel 4 memperlihatkan hasil Anova yang menjadi dasar penjelasan apakah hubungan kedua variabel independen dan variabel dependen memiliki signifikansi. Cara melihatnya adalah nilai signifikansi Sig. harus berada di bawah 0.05. Nilai Sig. menunjukkan angka 0.000 sehingga dapat dikatakan bahwa hubungan kepemimpinan transformasional dan kepuasan kerja dengan komitmen afektif signifikan.

Tabel 4. ANOVA

\begin{tabular}{llcl}
\hline Model & & F & Sig. \\
\hline 1 & Regression & 49,345 &, $000^{\mathrm{b}}$ \\
& $\begin{array}{l}\text { Residual } \\
\text { Total }\end{array}$ & & \\
& & & \\
\hline
\end{tabular}

Sumber: Data Diolah.

Tabel 5 akan memperlihatkan hasil analisis regresi berikutnya. Tabel koefisien ini akan menjelaskan hubungan parsial (masing-masing) variabel independen dengan variabel dependen. Gaya kepemimpinan transformasional ternyata tidak memiliki pengaruh yang 
signifikan terhadap komitmen afektif (nilai signifikansi .052>0.05). Sedangkan kepuasan kerja memiliki pengaruh signifikan.

Tabel 5. Koefisien

\begin{tabular}{ccc}
\hline Model & B & Sig. \\
\hline 1 (Constant) & 9,528 & 0,000 \\
\hline Kepemimpinan & .140 &, 052 \\
Transformasional & .485 & 0,000 \\
\hline Kepuasan Kerja & &
\end{tabular}

Sumber: Data Diolah.

Hasil analisis jalur akan mengukur pengaruh langsung dan tidak langsung dari setiap variabel independen dengan variabel dependen. Tabel 6 menyajikan hubungan langsung dan tidak langsung tersebut. Berdasarkan tabel tersebut nampak bahwa pengaruh total yang diperoleh, 0.328 tidak berbeda dengan nilai $\mathrm{R}^{2}$ pada Tabel 6 . Kepemimpinan transformasional dan kepuasan kerja secara bersama-sama dapat meningkatkan komitmen afektif karyawan. Nilai 0.328 atau 32.8\% memperlihatkan pengaruh kedua variabel ini relatif tidak terlalu kuat (di bawah 50\%). Meski demikian, organisasi masih perlu mengidentifikasi faktor-faktor lain yang juga dapat berpengaruh terhadap peningkatan komitmen afektif.

Tabel 6. Pengaruh Langsung \& Tidak Langsung

\begin{tabular}{lrrr}
\hline \multicolumn{4}{c}{ Pengaruh Terhadap Komitmen Afektif } \\
& Langsung & Tidak Langsung \\
\hline Transformasional & 0,02 & 0,029 & 0,049 \\
Kepuasan Kerja & 0,24 & 0,039 & 0,279 \\
TOTAL & & & 0,328 \\
\hline
\end{tabular}

Sumber: Data Diolah.

\section{Pembahasan}

Menggunakan industri genteng Jatiwangi sebagai sampel, penelitian ini membahas tentang hubungan antara kepemimpinan transformasional, kepuasan kerja, dan komitmen afektif karyawan. Tujuan dari penelitian ini diharapkan dapat memperkaya pengetahuan dalam bidang perilaku organisasi khususnya terkait variabelvariabel yang diteliti. Penelitian ini menemukan bahwa kepemimpinan transformasional memiliki hubungan signifikan positif terhadap kepuasan kerja. Hal yang menjadi pembeda adalah besaran nilai korelasinya. Penelitian kali ini memperoleh nilai 0.581 yang tergolong sangat kuat jika dibandingkan penelitian terdahulu yang rata-rata hanya mendapatkan nilai korelasi sebesar 0.445 . Organisasi yang ingin meningkatkan persepsi kepuasan kerja karyawannya dapat menerapkan gaya kepemimpinan trnasformasional. Gaya kepemimpinan ini juga dikenal sebagai salah satu bentuk interaksi ideal dimana pimpinan dan karyawan memiliki kedekatan dalam menjalankan pekerjaannya.

Selanjutnya terkait dengan Hipotesis $\mathrm{H} 2$ hasil penelitian menunjukkan bahwa gaya kepemimpinan transformasional memiliki hubungan signifikan positif dengan komitmen afektif. Ini berarti $\mathrm{H} 2$ juga dapat dibuktikan melalui penelitian ini. Hasil yang diperoleh sama dengan penelitian dari Korea Selatan (Kim, 2013), Bosnia dan Herzegovina (Mujkic et al., 2014), India (Pradhan \& Pradhan,2015), Ghana (Gyensare et al., 2016), Amerika Serikat (Allen et al., 2017), Pakistan (Islam et al., 2018). Bahkan 
nilai korelasi dari penelitian ini lebih tinggi (0.422) dibandingkan dengan rata-rata korelasi dari hasil penelitian sebelumnya (0.343).

Hipotesis H3 terakhir yang membahas tentang korelasi antar variabel adalah terkait dengan adanya korelasi signifikan dan positif antara kepuasan kerja dengan komitmen afektif. Hasil korelasi yang diperoleh adalah 0.566 yang berarti terdapat hubungan signifikan dan positif. Hasil ini mendukung penelitian sebelumnya yang dilakukan di Indonesia (Luturlean et al., 2018), Turkey (Tosun \& Ulusoy,2017), India (Saha \& Kumar, 2018), China (Kuo,2014), Pakistan (Imam et al., 2013), Arab Saudi(Nazneen \& Miralam,2017).

Hipotesis $\mathrm{H} 4$ terkait pengaruh secara simultan dari kedua variabel independen terhadap komitmen afektif. Penelitian ini membuktikan bahwa kepemimpinan transformasional dan kepuasan kerja berpengaruh secara simultan terhadap komitmen afektif karyawan. Besarnya pengaruh adalah 33.4\% seperti yang tersaji pada Tabel 4. Besar pengaruh dapat dikatakan tidak terlalu kuat karena berada pada titik tengah $(50 \%)$ meski tidak terlalu jauh. Nilai persentase tersebut memberikan pemahaman bagi organisasi untuk melihat faktor-faktor lain yang mungkin bisa mempengaruhi pembentukan komitmen afektif karyawan. Beberapa faktor yang dapat dijadikan pilihan oleh organisasi antara lain;dukungan organisasi, leader-member exchange, kekuatan manajerial, masa jabatan organisasi, motivasi, persepsi tanggung jawab sosial perusahaan, keadilan prosedural, keseimbangan kehidupan kerja, stress kerja, dan budaya organisasi.

Hipotesis H5 terakhir dalam penelitian ini adalah terdapatnya hubungan yang signifikan positif antara kepemimpinan transformasional melalui kepuasan kerja. Penelitian ini memperlihatkan bahwa pengaruh langsung yang diberikan kepemimpinan transformasional terhadap komitmen afektif sebesar $2 \%$. Pengaruh tidak langsung yang dihasilkan adalah sebesar 2,9\%. Maka pengaruh total yang didapatkan adalah sebesar 2 $\%+2,9 \%=4,9 \%$. Berdasarkan hasil diatas diketahui bahwa nilai pengaruh langsung lebih kecil daripada nilai pengaruh tidak langsung. Hasil ini menunjukkan bahwa secara tidak langsung kepemimpinan transformasional melalui kepuasan kerja memiliki pengaruh signifikan terhadap komitmen afektif. Perlu dicatat bahwa penelitian ini dilakukan dengan data yang diperoleh secara cross-section (satu waktu tertentu). Penggunaan data time series bisa saja mengubah hasil ini. Perubahan ini mungkin disebabkan fluktuasi pengalaman positif dan negatif karyawan ketika berinteraksi dengan pimpinan mereka.

\section{KESIMPULAN}

Penelitan ini membuktikan bahwa kepemimpinan transformasional dan kepuasan kerja memiliki hubungan yang signifikan dan positif terhadap komitmen afektif karyawan yang bekerja di industri genteng Jatiwangi. Kepuasan kerja juga memilki korelasi positif dengan komitmen afektif. Dengan demikian ketiga variabel penelitian memiliki korelasi yang positif. Berdasarkan pernyataan sebelumnya yang menjawab hipotesis yang dibangun sebelumnya yaitu $\mathrm{H} 1, \mathrm{H} 2$, dan $\mathrm{H} 3$. Penelitian ini juga menjawab hipotesis $\mathrm{H} 4$ tentang kepemimpinan dan kepuasan kerja secara simultan berpengaruh terhadap komitmen afektif karyawan. Kepemimpinan transformasional bisa menciptakan suasana kerja nyaman dan positif dan membuat karyawan merasa puas yang pada akhirnya dapat membantu meningkatkan komitmen afektif mereka. Terakhir, penelitian ini juga membuktikan bahwa H5 telah terjawab tentang kepemimpinan transformasional memiliki hubungan signifikan dan positif terhadap komitmen afektif melalui kepuasan 
kerja. Pemimpin dalam organisasi diharapkan dapat meluangkan waktu untuk dapat berinteraksi dengan bawahan, melibatkan karyawan dalam setiap aktivitasnya, dan membuat karyawan puas akan dengan pekerjaan akan meningkatkan komitmen afektif karyawan yang berada di industri genteng Jatiwangi. Organisasi yang dikelola oleh pemimpin transformasional cenderung memiliki kesempatan lebih besar untuk mencapai tujuan organisasinya. Pemimpin dalam organisasi bukan saja berkontribusi bagi perusahaan akan tetapi juga bagi karyawan dan diri mereka sendiri. Hal ini akan menciptakan situasi yang saling menguntungkan bagi semua pihak.

Berdasarkan hasil yang didapat, perusahaan harus terus meningkatkan perhatian terhadap karyawan seperti gaji, pengembangan karir, interaksi atasan dan bawahan yang baik, interaksi sesama rekan kerja yang positif, serta melakukan pengembangan atau merancang ulang pekerjaan agar tidak membosankan dan memberi tantangan yang memadai. Walaupun kepemimpinan transformasional memiliki hubungan yang tidak terlalu kuat dalam meningkatkan komitmen afektif tapi tetap harus menigkatkan keefektifan penerapan kepemimpinan transformasional di industri tersebut. Karena pimpinan yang dipersepsikan dekat dengan karyawan, mampu memberikan solusi, serta dapat membangun motivasi kerja merupakan pemimpin yang lebih disukai oleh karyawan.

Organisasi disarankan untuk melakukan studi lebih lanjut untuk mengidentifikasi aspek-aspek lain yang mungkin memiliki korelasi kuat dengan komitmen afektif seperti motivasi, gaya kepemimpinan lain, kondisi kerja, dan dukungan organisasi. Variabelvariabel ini dapat dieksplorasi untuk meningkatkan praktik sumber daya manusia yang bertujuan untuk meningkatkan komitmen afektif karyawan . Jika tercapai, maka mereka dapat mengandalkan sumber daya manusia sebagai keunggulan kompetitif untuk bisnis mereka.

\section{DAFTAR PUSTAKA}

Adams, J., Khan, H.T.A., Raeside, R. (2013). Research Methods for Business and Social Science Students (Second Edition). New Delhi: SAGE.

Allen, G.W., Attoh, P.A., Gong, T. (2017). Transformational leadership and affective organizational commitment: mediating roles of perceived social responsibility and organizational identification. Emerald Publishing Limited. Vol. 13 No. 3 2017, pp. 585-600, DOI 10.1108/SRJ-11-2016-0193.

Allen, N. J. \& J. P. Meyer. 1990. "The Measurement and Antecedents of Affective, Continuance and Normative Commitment." Journal of Occupational Psychology, 63: 1-18.

Bayram, H., Dinc, S. (2015). Role of Transformational Leadership on Employee's Job Satisfaction: the Case of Private Universities in Bosnia and Herzegovina. Academic Publishing House Researcher. Vol.93, No. 4, 270-281, DOI: 10.13187/er.2015.93.270.

Baysak, B., Yener, M.I. (2015). The relationship between perceived leadership style and perceived stress on hospital employees. Procedia - Social and Behavioral Sciences. 207, 79-89, doi: 10.1016/j.sbspro.2015.10.159. 
Casimir, G., Ng, Y.N.K., Wang, K.R., \& Ooi, G. (2014). The relationships amongst leader-member exchange, perceived organizational support, affective commitment, and in-role performance A social-exchange perspective. Leadeship and Organization Development Journal. Vol.35, No.5, pp.366-385, DOI 10.1108/LODJ-04-2012-0054.

Chan, S.C.H., Mak, W.M. (2014). Transformational leadership, pride in being a follower of the leader and organizational commitment. Emerald Group Publishing Limited. Vol. 35 No. 8, pp. 674-690, DOI 10.1108/LODJ-12-09-0076.

Charbonneau, D., \& Wood, V.M. (2018). Antecedents and outcomes of unit cohesion and affective commitment to the Army. Military Phychology. Vol.30, No. 1,43-53, https://doi.org/10.1080/08995605.2017.1420974.

Colquitt, J.A., Lepine, J.A., \& Wesson, M.J. (2013). Organizational Behavior: Improving Performance and Commitment in The Workplace Fourth Edition. New York: McGraw-Hill.

Dlamini, N.N.N., Garg, P.A., \& Muchie, P.M. (2017). The impact of transformational leadership style on organisational commitment in the hospitality industry. African Journal of Hospitality, Tourism and Leisure. Vol. 6 (3), 1-21, http://www.ajhtl.com/uploads/7/1/6/3/7163688/article_32_vol_6_3_2017.pdf.

Donald, M.F., Lucia, M.E., Victor, N.M. (2016). The Relationship Between Job Satisfaction and Organizational Commitment Among Academiv Staff Members In A Selected Higher Education Institution. The WEI International Academic Conference Proceedings. 38-47, https://www.westeastinstitute.com/wpcontent/uploads/2016/05/Fumani-Mabasa_2.pdf

Edison, E., Anwar, Y., Komariyah, I. (2016). Manajemen Sumber Daya Manusia. Bandung: Alfabeta.

English, B., Morrison, D., \& Chalon, C. (2010). Moderator effects of organizational tenure on the relationship between psychological climate and affective commitment. Journal of Management Development. Vol. 29, No.4, pp. 394-408, DOI 10.1108/02621711011039187.

Giovanita, D., \& Mangundjaya, W.L. (2017). Transformational Leadership vs Change Self-Efficacy and Its Impact on Affective Commitment to Change. Journal of Management and Marketing Review. Vol.2, No. 4, 13-18. https://ideas.repec.org > gtr > gatrjs > jmmr 170 .

Giunchi, M., Chambel, M.J., \& Ghislieri, C. (2015). Contract moderation effects on temporary agency workers' affective organizational commitment and perceptions of support. Personnel Review. Vol.44, No.1, pp.22-38, DOI 10.1108/PR-03-20140061.

Griffin, R.W., Moorhead, G. (2014). Organizational Behavior: Managing People and Organizations, Eleventh Edition. South-Western:Cengage Learning. 
Gyensare, M.A., Anku-Tsede, O., Sanda, M., Okpoti, C.A. (2016). Transformational leadership and employee turnover intention The mediating role of affective commitment. Emerald Group Publishing Limited. Vol. 12 No. 3, pp. 243-266, DOI10.1108/WJEMSD-02-2016-0008.

Imam, A., Raza, A., Shah, F.T., \& Raza, H. (2013). Impact of Job Satisfaction on Facet of Organizational Commitment (Affective, Continuance and Normative Commitment): A Study of Banking Sector Employees of Pakistan. World Applied Sciences Journal. 28 (2), 271-277, DOI: 10.5829/idosi.wasj.2013.28.02.12468.

Islam, T., Tariq, J., Usman. (2018). Transformational leadership and four-dimensional commitment Mediating role of job characteristics and moderating role of participative and directive leadership styles. Emerald Group Publishing Limited. Vol. 37 No. 9/10, pp. 666-683, DOI 10.1108/JMD-06-2017-0197.

Ivancevich, J.M., Konopaske, R., Matteson, M.T. (2014). Organizational Behavior and Management Tenth Edition. New York:McGraw-Hill.

Jalilvand, M.R., \& Vosta, L.N. (2015). Examining the relationship between managerial power and affective organizational commitment An empirical study in the sport sector of Iran. Sport, Business and Management: An International Journal. Vol. 5, No. 4, pp. 344-364, DOI 10.1108/SBM-04-2011-0041.

Javed, A., Anas, M., Abbas, M., Khan, A.I. (2017). Flexible Human Resource Management And Firm Innovativeness: The Mediating Role Of Innovative Work Behavior. Journal of Human Resource Management. Vol.20, No.1, 31-41, https://www.jhrm.eu/2017/05/31-flexible-human-resource- management-and-firminnovativeness-the-mediating-role-of-innovative-work-behavior/.

Kalangi, R. (2015). Pengembangan Sumber Daya Manusia dan Kinerja Aparat Sipil Negara di Kabupaten Kepulauan Sanghie Provinsi Sulawesi Utara. Jurnal LPPM Bidang EkoSosBudKum, Vol.2, No.1, 1-18, https://ejournal.unsrat.ac.id/index.php/lppmekososbudkum/article/view/9296.

Kim, H.Y. (2013). Transformational Leadership, Organizational Clan Culture, Organizational Affective Commitment, and Organizational Citizenship Behavior: A Case of South Korea's Public Sector. Public Organization Review, Vol. 14, Issue 3, 397-417, DOI 10.1007/s11115-013-0225-z.

Kumari, N., \& Afroz, N. (2013). The Impact of Affective Commitment in Employees Life Satisfaction. Global Journal of Management and Business Research $\begin{array}{llll}\text { Interdisciplinary. } & \text { Vol.3, } & \text { Issue. }\end{array}$ https://globaljournals.org/GJMBR_Volume13/4-The-Impact-of-AffectiveCommitment.pdf.

Kuo, S.Y. (2015). Occupational Stress, Job Satisfaction, and Affective Commitment to Policing Among Taiwanese Police Officers. Police Quarterly, Vol. 18(1) 27-54, DOI: $10.1177 / 1098611114559039$. 
Loi, R., Lam, L.W., Ngo, H.Y., \& Cheong, S. (2015). Exchange mechanisms between ethical leadership and affective commitmen. Journal of Managerial Psychology. Vol. 30 No. 6, pp. 645-658, DOI 10.1108/JMP-08-2013-0278.

Luturlean, B.S., Prasetio, A.P, Firli, A., Mikola, G.A., \& Darmawan, M.A. (2018). Kepemimpinan Transformasional, Kepuasan Kerja, dan Komitmen Afektif pada Karyawan Perusahaan Bidang Konstruksi Milik Pemerintah di Medan. Jurnal Manajemen Indonesia, Vol. 18, No.3, 209-221, https://journals.telkomuniversity.ac.id/ijm/article/view/1733.

Menon, M.E. (2014). The relationship between transformational leadership, perceived leader effectiveness and teachers' job satisfaction. Journal of Educational Administration. Vol. 52 No. 4, pp. 509-528, DOI 10.1108/JEA-01-2013-0014.

Meyer, J.P. \& Allen, N.J. (1991). A Three Component Conceptualization of Organizational Commitment. Human Resource Management Review, Vol. 1, No. $1,61-89$.

Mujkic, A., Sehij, D., Rahimic, Z., Jusic, J. (2014). Transformational Leadership and Employee Satisfaction. Ekonomski/Ekonviews, Vol. 27, No. 2, 259-270, https://hrcak.srce.hr > file.

Mulyadi, D. (2015). Perilaku Organisasi dan Kepemimpinan Pelayanan. Bandung: Alfabet.

Nasra, M.A. \& Heilbrunn, S. (2015). Transformational Leadership and Organizational Citizenship Behavior in the Arab Educational System in Israel: The Impact of Trust and Job Satisfaction. Educational Management Administration \& Leadership, 1-17, DOI: 10.1177/1741143214549975.

Nazneen, A., \& Miralam, M.S. (2017). A Study of Affective, Continuance and Normative Commitments and its Impact on Job Satisfaction among the Faculty Members of Technical Universities. International Review of Management and Business Reserch. Vol.6, Issue. 4, 1427-1438, http://www.irmbrjournal.com/papers/1513074286

Northouse, P.G. (2016). Leadership : Theory and Practice Seventh Edition. United States: SAGE Publications.

Omar, M.K. (2013). Non Standard Work Arrangements and Affective Commitment: the Mediating Role of Work-Life Balance. Procedia - Social and Behavioral Sciences.Vol. 107, 4 - 12, doi : 10.1016/j.sbspro.2013.12.392.

Porter, J.A. (2015). The relationship between transformational leadership and organizational commitment in nonprofit long term care organizations: The direct care worker perspective. Creighton Journal of Interdisciplinary Leadership. Vol. 1, No. 2, 68 - 85, DOI: http://dx.doi.org/10.17062:CJIL.v1i2.13. 
Pradhan, S. \& Pradhan, R.K. (2015). An Empirical Investigation of Relationship among Transformational Leadership, Affective Organizational Commitment and Contextual Performance. Vision. 19(3) 227-235, DOI: 10.1177/0972262915597089.

Prasetio, A.P., Yuniarsih, T., \& Ahman, E. (2017). Perceived Work-Life Interface and Organizational Citizenship Behavior: Are The Job Satisfaction \& Organizational Commitment Mediates the Relations? (Study on Stars Hotel Employee in Indonesia). International Journal of Human Resource Studies, Vol.7,No.2,122135.

Riduwan, \& Kuncoro, E.A. (2017). Cara Menggunakan dan Memakai Path Analysis (Analisis Jalur). Bandung : ALFABETA.

Rinandiyana, L.R., Kurniawati, A., Kurniawan, D. (2016). Strategi untuk Menciptakan Keunggulan Bersaing Melalui Pengembangan, Desain, dan Kualitas Produk (Kasus Pada Industri Pakaian Muslim di Kota Tasikmalaya. Jurnal Ekonomi Manajemen. Vol. 2, No.2, 105,113. jurnal.unsil.ac.id > index.php > jem > article > view.

Robbins, S.P., \& Judge, T.A. (2015). Perilaku Organisasi. Jakarta: Salemba Empat.

Saha, S., \& Kumar, S.P. (2017). Organizational culture as a moderator between affective commitment and job satisfaction Empirical evidence from Indian public sector enterprises. International Journal of Public Sector Management. Vol. 31 No. 2, pp. 184-206, DOI 10.1108/IJPSM-03-2017-0078.

Sayadi, Y. (2016). The effect of dimensions of transformational, transactional, and nonleadership on the job satisfaction and organizational commitment of teachers in Iran. Management in Education, 1-9, DOI: 10.1177/0892020615625363.

Stoilkovska, A., Ristovska, N., \& Gramatnikovski, S. (2015). Innovative Business Model For Competitive Advantage of The Companies. UTMS Journal of Economics. Vol. $6(1), 135-146$, utmsjoe.mk > files > 6-1-11-UTMS_Journal_of_Economics.

Sujarweni, V.W. (2015). SPSS Untuk Penelitian. Yogyakarta: Pustaka Baru Press.

Sun, Y., Gergen, E., Avilla, M., \& Grenn, M. (2016). Leadership and Job Satisfaction: Implications for Leaders of Accountants. American Journal of Industrial and Business Management, 2016, 6, 268-275, http://dx.doi.org/10.4236/ajibm.2016.63024.

Supardi. (2013). Aplikasi Statistika Dalam Penelitian Konsep Statistika Yang Lebih Komprehensif. Jakarta:Change Publication.

Susilawati, T.E. (2018). Pengaruh Komitmen Afektif, Kontinuan, dan Normatif pada Intensi Keluar. Optimal : Jurnal Ekonomi dan Kewirausahaan. Vol.12, No.2, 154170. https://doi.org/10.33558/optimal.v12i2.1687

Suwatno., \& Priansa, D.J. (2014). Manajemen SDM dalam Organisasi Publik dan Bisnis. Bandung: Alfabeta. 
Taniredza, T., Mustafidah, H. (2011). Penelitian Kuantitatif (Sebuah Pengantar). Bandung: Alfabeta.

Tosun, N., \& Ulusoy, H. (2017). The relationship of organizational commitment, job satisfaction and burnout on physicians and nurses?. Journal of Economics and Management. Vol. 28, No. 2, 90-111. DOI: 10.22367/jem.2017.28.06. 